\title{
Can microRNA become next-generation tools in molecular diagnostics and therapeutics? A systematic review
}

\author{
Vandana Saini ${ }^{*}$, Rajni Dawar, Shilpa Suneja, Sukanya Gangopadhyay and Charanjeet Kaur
}

\begin{abstract}
Background: MicroRNAs (miRNAs) represent a novel class of single-stranded RNA molecules of 18-22 nucleotides that serve as powerful tools in the regulation of gene expression. They are important regulatory molecules in several biological processes.

Main body: Alteration in the expression profiles of miRNAs have been found in several diseases. It is anticipated that miRNA expression profiling can become a novel diagnostic tool in the future.

Hence, this review evaluates the implications of miRNAs in various diseases and the recent advances in miRNA expression level detection and their target identification. A systematic approach to review existing literature available on databases such as Medline, PubMed, and EMBASE was conducted to have a better understanding of mechanisms mediating miRNA-dependent gene regulation and their role as diagnostic markers and therapeutic agents.

Conclusion: A clear understanding of the complex multilevel regulation of miRNA expression is a prerequisite to explicate the origin of a wide variety of diseases. It is understandable that miRNAs offer potential targets both in diagnostics and therapeutics of a multitude of diseases. The inclusion of specific miRNA expression profiles as biomarkers may lead to crucial advancements in facilitating disease diagnosis and classification, monitoring its prognosis, and treatment. However, standardization of methods has a pivotal role in the success of extensive use of miRNA expression profiling in routine clinical settings.
\end{abstract}

Keywords: Gene regulation, miRNA gene silencing, miRNA expression profiling, miRNA antagonists, miRNA mimics

\section{Background}

MicroRNAs (miRNAs) are 21-25 nucleotide, singlestranded, non-coding RNA molecules that play an important role in regulating gene expression. Following the discovery of the first miRNA, lin-4, in Caenorhabditis elegans in the year 1993, several miRNAs have been discovered with the recent development of high-throughput sequencing technologies and computational and bioinformatics prediction methods $[1,2]$. miRNAs play a vital role in the regulation of diverse processes, including cell

\footnotetext{
* Correspondence: vandanasaini2@gmail.com

Department of Biochemistry, Vardhmann Mahavir Medical College \&

Safdarjung Hospital, New Delhi 110029, India
}

proliferation, apoptosis, fat metabolism, hematopoietic differentiation, and regulation of immune system [3]. The aberrant miRNA expression has profound implications in a wide range of human diseases such as schizophrenia, diabetes, cancer, and infectious and autoimmune diseases [4]. The recent studies in relation to miRNA expression profiling are proving it to be clinically relevant to diagnosis, progression, and outcome of certain diseases [5].

Thus, this review overviews the implications of miRNAs in various diseases and the recent advances in molecular diagnostics and therapeutics. It will also provide

\section{Springer Open}

๑ The Author(s). 2021 Open Access This article is licensed under a Creative Commons Attribution 4.0 International License, which permits use, sharing, adaptation, distribution and reproduction in any medium or format, as long as you give appropriate credit to the original author(s) and the source, provide a link to the Creative Commons licence, and indicate if changes were made. The images or other third party material in this article are included in the article's Creative Commons licence, unless indicated otherwise in a credit line to the material. If material is not included in the article's Creative Commons licence and your intended use is not permitted by statutory regulation or exceeds the permitted use, you will need to obtain permission directly from the copyright holder. To view a copy of this licence, visit http://creativecommons.org/licenses/by/4.0/. 
noteworthy insights into human miRNA biogenesis and regulation.

\section{Main text \\ Methods}

The review was conducted following the methodology suggested by Arksey and O'Malley [6]. The search for relevant literature was conducted via Google search engine using the search terms "Micro-RNA", "mechanism of MicroRNA gene regulation", "MicroRNA in diseases", "miRNA function", "miRNAs as diagnostic markers", and "miRNA in therapeutics". Two authors independently searched through the literature, which was then compared, and duplicate articles were eliminated. Eventually, 25 unique academic publications were included in this review. Figure 1 shows the study selection process with the help of a PRISMA (Preferred Reporting Items for Systematic Reviews and Meta-Analyses) flow diagram [7]. A narrative synthesis was used to analyze the findings of the research articles.

\section{Biogenesis and gene regulation}

We need to foremost understand the current concepts of the mechanisms of miRNA-mediated gene regulation, in order to elucidate their probable target sites in molecular diagnostics and therapeutics. miRNA precursors are commonly found in clusters, within intergenic regions and introns of protein-coding genes $[8,9]$. The majority of miRNAs is transcribed by RNA polymerase II, following which, these primary miRNAs (pri-miRNAs) undergo processing by the microprocessor complex, consisting of an RNA-binding protein DGCR8 and a ribonuclease III enzyme, Drosha, to form precursor miRNAs (pre-miRNAs). Their transport into the cytoplasm is mediated by an exportin 5/RanGTP complex for further processing by cytoplasmic RNase III endonuclease Dicer to generate a mature miRNA duplex [10]. Finally, the miRNA duplex is incorporated into the Argonaute (Ago) family of proteins to generate an effector complex. Usually, one strand of miRNA (known as passenger strand) is degraded, whereas the other

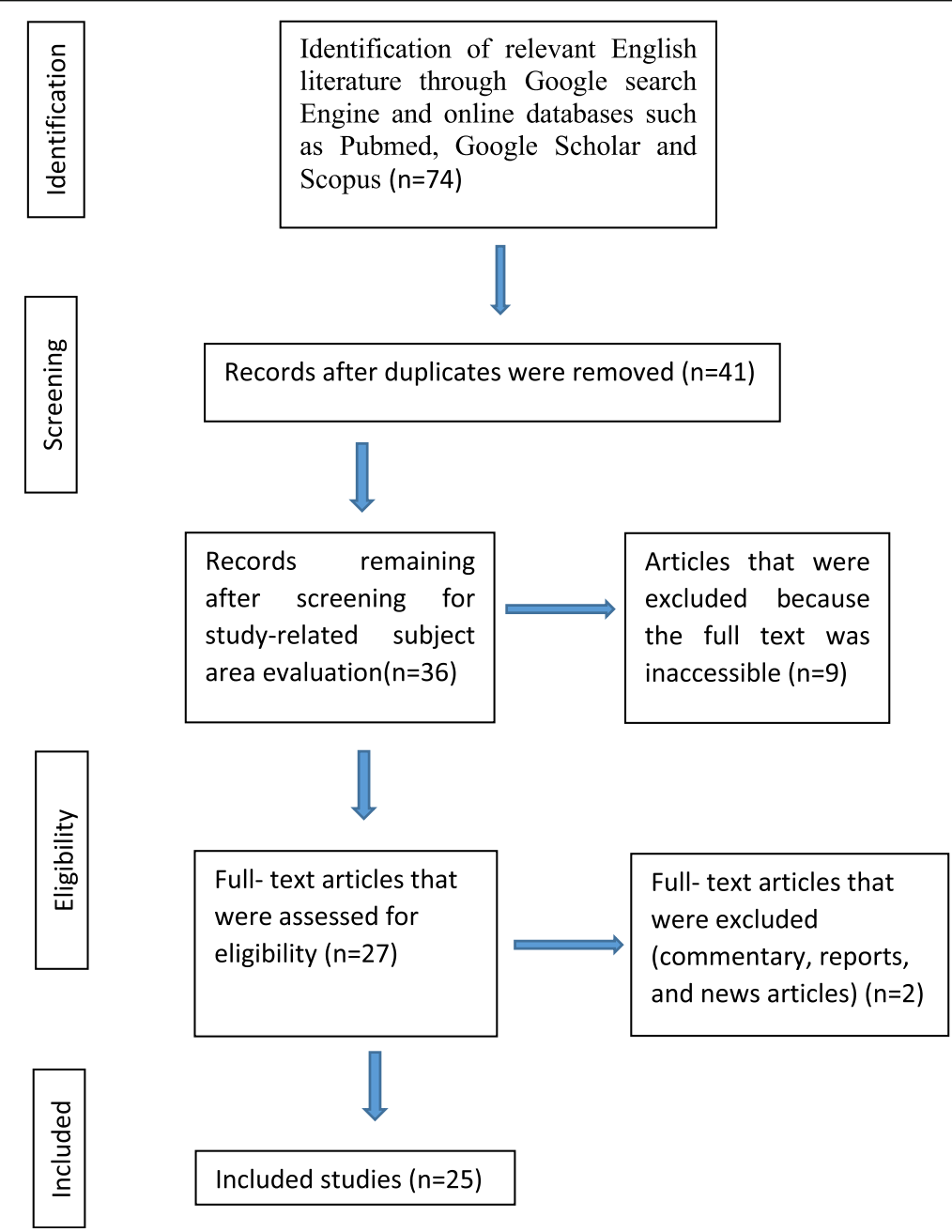

Fig. 1 Study selection process using PRISMA 
strand remained bound to Ago as mature miRNA (guide strand). Recently, non-canonical miRNA biogenesis pathways have also been elucidated which may be grouped into Drosha/DGCR8-independent and Dicerindependent pathways [11-13]. miRNAs interact with complementary sequences called miRNA response elements (MREs), usually at the 3' UTR of their target mRNAs to induce translational repression or degradation [14, 15]. Upregulation of a specific gene can increase the MRE load of a particular miRNA, thereby sequestering that miRNA away from other mRNA targets $[16,17]$. This concept may be utilized for therapeutic intervention as well. Following miRNA: target mRNA interaction, the formation of RNA-induced silencing complex (RISC) starts with the recruitment of the GW182 family of proteins and other effector proteins, followed by degradation by exoribonuclease [18]. Although most studies focus on how miRNAs inhibit gene expression, some have also reported microRNAmediated translational activation, involving AGO2 and FXR protein 1 instead of GW182 family proteins [19]. The biogenesis of miRNA and the miRNA-directed regulation of target mRNA is depicted in Fig. 2.
Increasing evidence suggests that extracellular miRNAs act as intercellular signaling molecules and can activate downstream signaling events, eventually leading to biological functions. miRNAs are present in nearly all body fluids such as serum, cerebrospinal fluid, saliva, breast milk, urine, tears, colostrum, peritoneal fluid, bronchial lavage, seminal fluid, and ovarian follicular fluid. These circulating miRNAs are associated with exosomes, microvesicles, and apoptotic bodies or bound with protective proteins, which confer them stability at room temperature for up to 4 days and in extreme conditions such as boiling, multiple freeze-thaw cycles, and high or low $\mathrm{pH}$. Therefore, they have immense potential to serve as excellent biomarkers for a variety of diseases [20].

\section{Oncogenic and tumor suppressor miRNAs}

Over the past decade, a multitude of miRNAs has been recognized as dysregulated in many disease states, particularly cancer. It is now evident that the aberrant miRNA expression profoundly affects cancer-related signaling pathways such as cell proliferation, cell cycle control, apoptosis, differentiation, migration, and metabolism [21, 22]. Quite a number of miRNAs have been categorized as oncogenic or

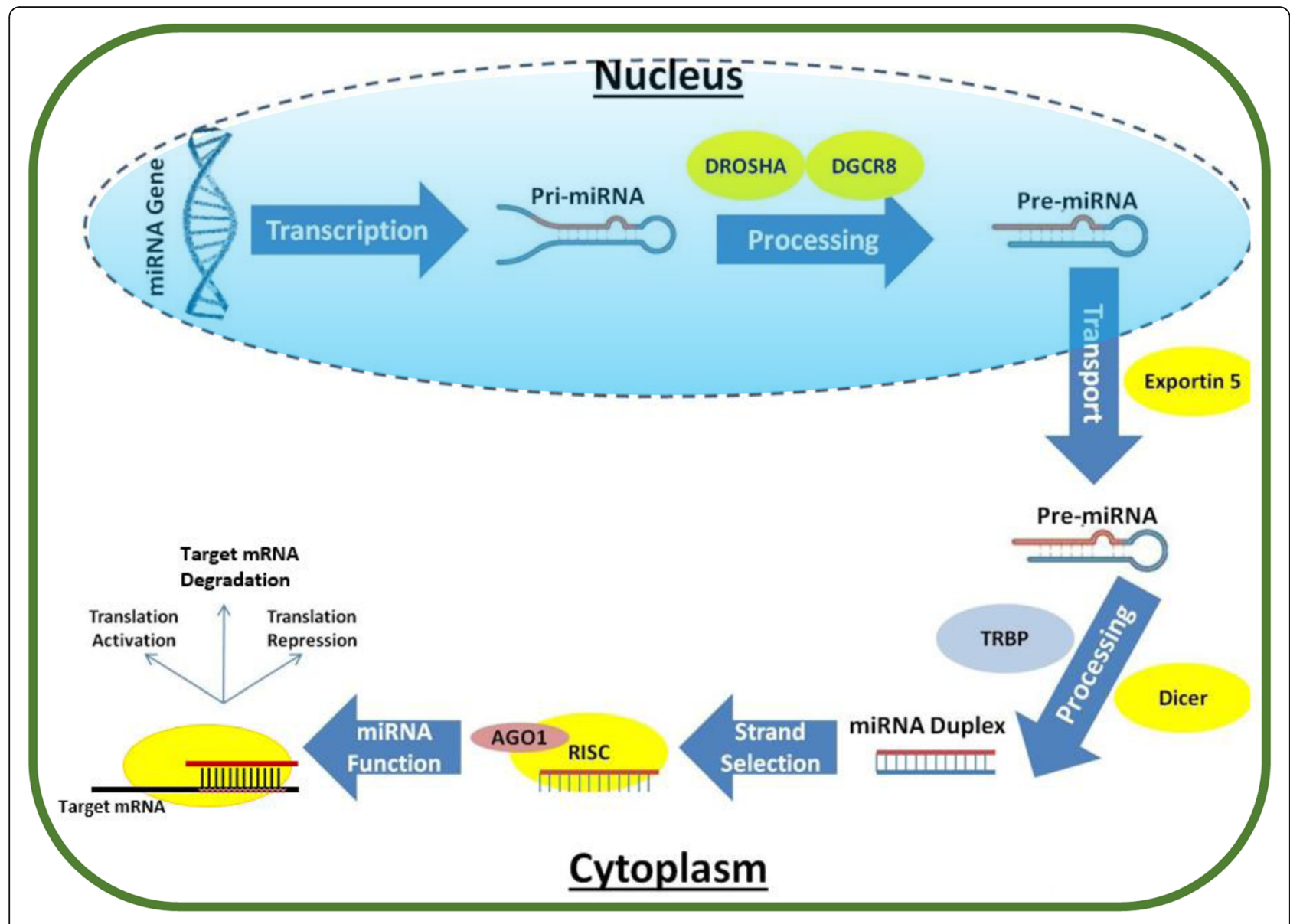

Fig. 2 Biogenesis of miRNA and formation of RISC leading to regulation of target mRNA by miRNA 
tumor suppressive. Nevertheless, in order to define a particular miRNA gene as an oncogene or a tumor suppressor can be challenging because their expression patterns are tissue-specific. Furthermore, a single miRNA can regulate multiple targets controlling different signaling pathways [23]. Thus, the functional status of a specific miRNA may change according to the setting, as a tumor suppressor in one situation and an oncogene in another.

miR-21 was termed as first oncogenic miRNA due to its universal overexpression in multiple malignancies such as glioblastomas and breast, colon, and pancreatic cancer [24]. Recently, it has been evidenced that miR-21 represses four tumor suppressor genes in order to promote cell transformation, tumor growth, invasion, and metastasis [25-27]. Similarly, miR-155 is found to be highly expressed in certain types of B cell lymphomas and breast, lung, cervical, and colon cancer [28-30]. miR-21 and miR-155 are being explored as promising therapeutic targets for controlling carcinogenesis [31]. On the other end of the spectrum, there is a loss of tumor suppressive actions of miR-15a and miR-16-1 in chronic lymphocytic leukemia and multiple myeloma and let-7 in lung and breast cancers [32]. In these cases, miRNA replacement therapy is being explored to restore the function of lost miRNAs in the diseased cells [33].

Atypical miRNA expression can also result from the altered activity of transcription factors in cancer cells. A classic example is transcription factor Myc, which binds to miRNA promoter and results in downregulation of miRNAs such as let-7, miR-15a/16-1, miR-26a, and miR-34 family members having anti-proliferative and pro-apoptotic activities [34, 35]. The transcription factor p53, commonly known as the guardian of the genome, is mutated in $50 \%$ of human cancers. To the exhaustive list of transcriptional targets of p53 are included the miRNAs such as miR-34 family, miR-107, miR-200, and miR-192 that inhibit tumorigenesis [36, 37]. This, in turn, further enhances tumor suppressor role of p53.

\section{Scope of miRNA-based diagnostics and therapeutics in human diseases}

miRNA is an emerging star in the field of diagnostics and therapeutics. As the regulatory role of miRNAs in the pathological processes of numerous diseases is being recognized, they are gradually entering as potential targets in diverse fields such as cancer, cardiovascular diseases, stroke, and neurological disorders such as Alzheimer's disease, multiple sclerosis, and viral infections $[38,39]$. This is bestowed to the fact that these circulating biomarkers are quite stable in serum and other body fluids. They are thermodynamically preserved under extreme conditions and can be detected by several techniques [40]. Moreover, miRNAs are quite consistent in formalin-fixed tissues. Their expression profiling is more reliable than mRNA profiling during the classification of different tumor types as well as identification of metastatic cancers of unknown primary origin [41-44]. Asuragen, a pioneering pharmaceutical company, initiated the first ever miRNA-based diagnostic test to differentiate between pancreatic cancer and pancreatitis [45]. There are ongoing trials going on consistently in the development of miRNA-targeted drugs for diverse diseases [46].

\section{miRNAs as diagnostic and prognostic markers in human diseases}

The list of miRNAs which may be used as potential biomarkers in diverse diseases is exhaustive. Studies have suggested that miR-30a, miR-126, miR-145, miR-122, miR-221, miR-223, and let-7 family members could be used as reliable markers for the early diagnosis of ischemic stroke. Further, miR-124-3p and miR-16 are potential diagnostic markers to discriminate hemorrhagic and ischemic stroke [47]. The expression profile of miR-30 has also been found to be altered in patients with acute myocardial infarction [48]. Elevated levels of circulating hsa-miR-133b may indicate patients requiring urgent coronary revascularization [49]. A panel of circulating miRNAs (hsa-miR132-3p, -150-5p, and -186-5p) could differentiate between patients with stable vs unstable angina [50]. Certain platelet-rich miRNAs have shown the prospect of been used as biomarkers in cardiac arrhythmias particularly atrial fibrillation [51]. miRNA expression profiling assays may provide valuable information to guide drug regimen selection, particularly in cancer. The high miR-21 expression is associated with a poor therapeutic outcome in patients with colon adenocarcinoma receiving fluorouracil-based chemotherapy [52]. MicroRNA-181a may serve as a novel diagnostic and prognostic indicator to monitor the involvement of the central nervous system in childhood acute leukemia [53].

miR-132 plays an important fine-tuning role in the physiological regulation of renin level, and thereby regulates electrolyte and blood volume homeostasis [54]. There is also a significant role of miRNAs in the pathogenesis of many allergic diseases, including asthma, eosinophilic esophagitis, allergic rhinitis, and eczema [55, 56]. Studies implying the involvement of microRNAs in mycobacterial infections are also being unraveled. MicroRNA signatures of tuberculosis as diagnostic biomarkers may provide new avenues for studying the immune response in this field [57]. Furthermore, a significant role of miRNAs has been attributed in the acute rejection process of renal allografts [58]. Despite advances in the field of allogeneic hematopoietic stem cell transplantation, the availability of sensitive biomarkers that can help in early detection of graft-versus-host disease (GVHD) and monitor its severity is quite limited. A recent study showed a panel comprising four circulatory miRNAs (miR-423, miR-199-3p, miR-93, 
and miR-377) that may detect GVHD in patients earlier compared to clinical diagnosis, which may aid in much required early intervention in such cases [59]. Table 1 shows important commercially available miRNA-based diagnostic markers.

\section{miRNA expression detection}

Both serum and tissue samples are suitable for miRNA expression profiling. The present techniques used for detecting miRNAs include Northern blotting (NB), quantitative reverse transcription-polymerase chain reaction (RT-qPCR), in situ hybridization (ISH), microarrays, and RNA sequencing.

NB is a readily available technique for miRNA analysis. It has an advantage of detecting both the miRNA precursors and mature miRNAs; however, it is expensive, laborious, time-consuming, and of low throughput. Further, NB is generally used for only semi-quantitative analysis $[60,61]$. RT-qPCR is a gold standard approach for detection and quantification of miRNA expression [62]. This technique has high sensitivity and specificity; nevertheless, it still has a drawback of low-throughput miRNA profiling [63]. Further, it is very demanding to design PCR primers of too small size since a typical miRNA measures 21-24 base pairs only [62].

The parallel analysis of a vast number of miRNAs may be achieved by miRNA microarray-based methods. The ample amount of high-quality RNA samples is a must here, which may be challenging at times. To overcome this drawback, microfluidic systems requiring only a small amount of input material and allowing single-cell miRNA profiling is now available [64]. Several technical variants such as immobilization chemistry and microarray chip signal detection methods have been developed in the last decade to facilitate easy and fast miRNA identification [65, 66]. The relative expression level of miRNA of interest across different tissue compartments can be readily determined using in situ hybridization even without RNA isolation. Microfluidic devices for automatic FISH applications are also being developed [67-69].

Emergence of next-generation sequencing (NGS) technology has provided a convenient platform to study and facilitate the discovery of novel circulating miRNAs, whereby it is possible to sequence multiple samples at one time. In comparison to microarray technology, NGS is more sensitive and specific and does not suffer from issues such as background noise and cross-hybridization; nevertheless, the high expense comes as a hurdle for its extensive usage in routine laboratories [70]. There is also an advancement of sensitive technologies such as silicon miRNA biosensors and carbon nanotube hybrids that have been developed for miRNA detection [71-74].

\section{miRNA target prediction tools}

It is known that a vast number of targets occur for any given miRNA. The computational approach model facilitates the process of narrowing down the potential target sites for an individual miRNA. There is a comprehensive list of available miRNA target prediction tools, each with a distinct approach to miRNA target prediction. Some popular online target prediction tools are miRandamirSVR, TargetScan, DIANA-micro T-CDS, TargetMiner, SVMicrO, and RNAhybrid [75]. These software tools have enormous capabilities, are easy to use, and ensure periodic updates and maintenance of the software.

However, it is noteworthy that these online tools cannot totally assure the actual targets of the miRNA. This is because, apart from seed matching and binding of complementary RNA strands, the factors that affect the targets of a particular miRNA include structural accessibility to 3' UTR of the mRNA, epigenetic modifications preventing miRNA binding, and the presence of competing endogenous RNAs [76]. The current limitations in miRNA target prediction tools will definitely be overcome as we gain more understanding of the processes of gene regulation.

\section{miRNA in point of care diagnostics}

The point-of-care (POC) diagnostics is an everexpanding field aiming to achieve a better patient outcome on the basis of early diagnosis. The development of POC systems for miRNA detection is widely spreading its wings in the horizon. The current strategies for miRNA quantification such as NB, ISH, RT-qPCR, microarrays, and NGS have their limitations at POC testing level; therefore, new technologies are constantly being explored for detection of miRNA in this domain.

The first POC technique of interest is isothermal amplification that can rapidly and efficiently amplify small nucleic acids without precise control of temperature cycling under simple conditions. A number of isothermal amplification techniques have been developed lately, such as branched rolling circle amplification (BRCA),

Table 1 Commercially available miRNA-based diagnostics

\begin{tabular}{llll}
\hline Diagnostic marker & Number of miRNAs in panel & Disorder & Company \\
\hline ThyraMIR/ThyGENX & 10 & Thyroid cancer & Interpace Diagnostics/Asuragen \\
OsteomiR & 19 & Osteoporosis & TAmiRNA \\
ThrombomiR & 11 & Cardiovascular diseases & TAmiRNA \\
miRview mets & 64 & Cancers of unknown primary origin (CUP) & Rosetta Genomics/Precision Therapeutics \\
\hline
\end{tabular}


exponential amplification reaction (EXPAR), hybridization chain reaction (HCR), catalytic hairpin assembly (CHA), strand-displacement amplification (SDA), duplex-specific nuclease signal amplification (DSNSA), and loop-mediated isothermal amplification (LAMP) [77]. Lateral flow assay (LFA)-based POC devices are one of the most convenient systems used for target miRNA detection. These devices are easy to operate, reasonably priced, highly sensitive, and specific due to minimum interferences [78, 79]. Lateral flow nucleic acid biosensors for detection of miRNA-21 and miRNA-224 have been developed recently [80, 81]. A pHresponsive miRNA amplification method has been developed by Feng et al. to quantify miRNA-21 in cancer cells [82], and the results were comparable with that of RTqPCR analysis. Oligonucleotide template reactions have been successfully applied to a wide range of chemistries. The procedure is isothermal, highly cost-effective, and does not require any amplification step. This method allows the quantitative identification of circulating miRNA biomarkers, such as miR-375, miR-141, and miR-132, in blood samples [83, 84].

Nano beads and electrochemical and microfluidic chipbased systems are also suited for POC diagnostics wherein miRNA can be directly detected in the clinical samples without any amplification $[85,86]$. Nevertheless, the development of POC for miRNA detection is still in an infant stage and needs further research and development.

\section{miRNA in therapeutics}

The recent understanding of the role of miRNAs in the pathogenesis of several diseases anticipates that miRNAs are the next important class of therapeutic molecules. There are two strategies via which miRNAs may be used in the development of new therapies. Firstly, miRNA antagonists could provide a therapeutic benefit by lowering down the upregulated endogenous miRNA expression, and thereby leading to the regulation of target gene(s) in diseased tissues [87, 88]. One of the classic examples is that of miR-122, a liver-specific miRNA, which plays an important role in the replication of hepatitis $\mathrm{C}$ virus (HCV) and is found to be upregulated in HCV-positive patients [89-91]. Miravirsen, a modified locked nucleic acid (LNA) miRNA antagonist under clinical trial, is an experimental drug for the treatment of such patients. It acts by sequestering and inhibiting miR- 122 from binding to the HCV genome, thereby preventing its multiplication [92]. These promising results foresee the potential of LNA-associated miRNA in treating other refractory diseases such as cancer. Peptide nucleic acids (PNA) are also analogs with high stability and specificity with a neutral charge, therefore easier to transfer in the biological system. A successful example is that of naked PNA-based antisense miR-155, which causes specific inhibition of $\mathrm{B}$ cell population in cultures or mouse models [93, 94]. This drug is considered as an appropriate research candidate for therapeutic intervention to treat different kinds of leukemia.

The second line of treatment in relation to miRNA is miRNA replacement therapy where miRNA mimics, such as miR-34a and let-7, are used to restore the function of lost miRNAs in the specific cells [33, 95, 96]. Similarly, miR-143/145 cluster has been found lost in a variety of cancers, and their re-expression with the help of miRNA mimics is considered a promising mode of therapy [97]. The fact that the systemic administration of a liposome-formulated miR-143/145 expression vector resulted in reduced outgrowth of pancreatic cancer supports the concept well [98]. Table 2 compiles some of the ongoing projects on miRNA-based therapeutics. miRNA-based candidate drugs are still in the developmental phase, and none has yet been approved for medical intervention.

miRNA delivery to the target tissue has been an active area of research. This will not only prevent side-effects of drugs or genes on other body tissues but also will possibly be more effective due to specific tissue being targeted by the maximum concentration of miRNA therapy. However, miRNA replacement therapy can be challenging due to factors such as rapid degradation by RNase, triggering of the immune response, insufficient cellular uptake, and possible cytotoxicity. Both viral and non-viral vectors are available for miRNA delivery; however, the major disadvantage with viral vectors is the stimulation of the immune system. Therefore, non-viral vectors and synthetic carriers are more appropriate. These carriers may be classified as lipid-based, low molecular weight polyethyleneimine-based nanoparticles, dendrimer-based, poly lactide-co-glycolide (PLGA) particles, and other non-viral miRNA carriers [99, 100]. Intranasal topical delivery of the miRNA mimics/ antagonists to the lung can potentially be used in the treatment of allergic diseases [101]. Nevertheless, there still remain hurdles in tissue-specific targeting and delivery of these small therapeutic molecules.

\section{Future prospectives}

Many more miRNAs and their functions are expected to be explored soon with ever-evolving sequencing technologies. Additionally, more insight will be gained into the diagnosis and mechanisms of miRNA regulation conclusively. Since several miRNAs have multiple target genes, therefore, what predicts the relationship between multiple members of a miRNA gene family and multiple target genes remains an inevitable question to be answered in the future. The study of compartmentalization of miRNAs within body fluids is among one of the interesting fields of future research. 
Table 2 Ongoing projects on miRNA-based therapeutics

\begin{tabular}{llllll}
\hline Drug name & Drug type & Target miR & Disorder & Clinical trial number/phase & Company \\
\hline Miravirsen & AntagomiR & miR-122 & Hepatitis C & $\begin{array}{l}\text { NCT02452814/phase 2 complete } \\
\text { NCT01200420/phase 2 (complete) }\end{array}$ & Roche/Santaris \\
MRG-201 (Remlarsen) & miRNA mimic & miR-29b & Fibrosis, keloid & NCT03601052/phase 2 (recruiting) & Miragen Therapeutics (now Synlogic) \\
MRG-106 (cobomarsen) & AntagomiR & miR-155 & T cell lymphoma & NCT03713320/phase 2 (recruiting) & Miragen Therapeutics (now Synlogic) \\
MRG-110 & AntagomiR & miR-92 & Heart failure & NCT03603431/phase 1 (recruiting) & Miragen Therapeutics (now Synlogic) \\
Mesomir-1 & miRNA mimic & miR-16 & Mesothelioma & NCT02369198/phase 1 (complete) & ENGenelC \\
ABX464 & miRNA mimic & miR-124 & Ulcerative colitis & NCT04023396/phase 2 (recruiting) & Abivax \\
\hline
\end{tabular}

The young developing field of miRNAs is likely to advance many preclinical projects to humans in the coming decade. The entry of miRNAs from the laboratory to the pharmaceutical industry is showing encouraging results. The use of extracellular miRNAs as molecular biomarkers in diverse diseases is a very attractive and promising concept. Additionally, they might offer advantages of reflecting specific cellular pathophysiological alterations. They could also allow early diagnosis and identification of subjects at risk before the actual appearance of the disease.

Although miRNAs may be labeled as versatile biomarkers well-suited for reflecting the pathophysiological processes underlying diseases, there are still a number of limitations. The large variation observed for miRNAs within the same population could make the identification of diagnostic range very challenging. Further studies are required to confidently differentiate between "normal" and "altered" levels of miRNA expression, specific to a particular tissue. They may also have to be adjusted according to the race, gender, and age. The present scenario shows technical difficulties and variations in high-throughput profiling studies between labs and across different platforms. Standardization of universal procedures such as the collection of sample, extraction, storage, profiling techniques, and statistical comparison of different techniques along with rigorous quality control will pave the way for induction of miRNA expression profiling in routine diagnostics to a large extent.

The need of the hour is alternative methodological approaches for measurement of circulating miRNAs that are reliable, fast, and cheaper. The non-invasive sources of body fluids such as saliva and urine for the measurement of miRNA expression still remain unexplored to a larger extent. In the burgeoning field of RNA therapeutics, a major challenge also lies in the targeted delivery of miRNA mimics or antagonists to diseased cells in vivo. Furthermore, choosing the most appropriate technology to modulate the miRNA expression is also a difficult task. With many kinds of research ongoing in this field, miRNA mimics may be used as an effective therapeutic method in cancers and other diseases as well in near future.

\section{Conclusions}

The field of miRNAs is like a rising star which has gradually advanced from an infant stage to the level where miRNAs are rapidly entering the clinic as important diagnostic and promising therapeutic tools. This review provides an overview of a multitude of technologies that have been developed for miRNA quantitation, profiling, and target detection, and suggests relevant evidence for future research directions on applied aspects of miRNA in clinical settings. A study of specific miRNA expression profiles may lead to crucial advancements for diagnosis, facilitating disease classification, monitoring prognosis, and treatment. The development of miRNAtargeted drugs is an arduous task, and more trials are must in the area of RNA therapeutics.

\section{Abbreviations}

GVHD: Graft-versus-host disease; HCV: Hepatitis C virus; ISH: In situ hybridization; LFA: Lateral flow assay; LNA: Locked nucleic acids; miRNA: MicroRNA; MRE: miRNA response elements; NB: Northern blotting; NGS: Next generation sequencing; PRISMA: Preferred Reporting Items for Systematic Reviews and Meta-Analyses; PLGA: Poly lactide-co-glycolide; PNA: Peptide nucleic acids; POC: Point of care; RISC: RNA-induced silencing complex; RT-qPCR: Reverse transcription-polymerase chain reaction

\section{Acknowledgements}

Not applicable.

\section{Authors' contributions}

All authors listed have made a substantial and intellectual contribution to the work and approved it for publication. VS substantially contributed to the conception, design, literature search, data acquisition, manuscript preparation, and manuscript editing. RD contributed to the literature search, data acquisition, manuscript preparation, manuscript editing, and manuscript review. SS contributed to the literature search, data acquisition manuscript drafting, and manuscript review. SG contributed to the definition of the intellectual content, manuscript editing, and manuscript review. CK substantially contributed to manuscript editing and revision, and manuscript review. All authors read and approved the final manuscript.

\section{Funding}

Not applicable.

Availability of data and materials

All data analyzed during this study is included in this published article in the references section.

Ethics approval and consent to participate

Not applicable.

Consent for publication

Not applicable. 


\section{Competing interests}

The authors declare that they have no competing interests.

\section{Received: 22 September 2020 Accepted: 10 December 2020} Published online: 25 January 2021

\section{References}

1. Lee RC, Feinbaum RL, Ambros V (1993) The C. elegans heterochronic gene lin-4 encodes small RNAs with antisense complementarity to lin-14. Cell 75: 843-854

2. Wightman B, Ha I, Ruvkun G (1993) Posttranscriptional regulation of the heterochronic gene lin-14 by lin-4 mediates temporal pattern formation in C. elegans. Cell 75:855-862

3. He L, Hannon GJ (2004) MicroRNAs: small RNAs with a big role in gene regulation. Nat Rev Genet 5:522-531

4. Lin X, Zhan J-K, Wang Y-J, Tan P, Chen Y-Y, Deng H-Q et al (2016) Function, role, and clinical application of microRNAs in vascular aging. BioMed Res Int. https://doi.org/10.1155/2016/6021394

5. MacFarlane L-A, Murphy PR (2010) MicroRNA: biogenesis, function and role in cancer. Curr Genomics 11:537-561

6. Arksey H, O'Malley L (2005) Scoping studies: towards a methodological framework. Int J Soc Res Methodol 8:19-32

7. Moher D, Liberati A, Tetzlaff J, Altman DG (2009) The PRISMA Group Preferred reporting items for systematic reviews and meta-analyses: the PRIS MA statement. PLoS Med. https://doi.org/10.1371/journal.pmed.1000097

8. De Rie D, Abugessaisa I, Alam T, Arner E, Arner P, Ashoor H et al (2017) An integrated expression atlas of miRNAs and their promoters in human and mouse. Nat Biotechnol 35:872-878

9. Kim YK, Kim VN (2007) Processing of intronic microRNAs. EMBO J 26:775-783

10. Denli AM, Tops BB, Plasterk RH, Ketting RF, Hannon GJ (2004) Processing of primary microRNAs by the microprocessor complex. Nature 432:231-235

11. Ruby JG, Jan CH, Bartel DP (2007) Intronic microRNA precursors that bypass Drosha processing. Nature 448:83-86

12. Babiarz JE, Ruby JG, Wang Y, Bartel DP, Blelloch R (2008) Mouse ES cells express endogenous shRNAs, siRNAs, and other microprocessorindependent, Dicer-dependent small RNAs. Genes Dev 22:2773-2785

13. Xie M, Li M, Vilborg A, Lee N, Shu MD, Yartseva V et al (2013) Mammalian 5'capped microRNA precursors that generate a single microRNA. Cell 155: 1568-1580

14. Huntzinger E, Izaurralde E (2011) Gene silencing by microRNAs: contributions of translational repression and mRNA decay. Nat Rev Genet 12:99-110

15. Ipsaro JJ, Joshua-Tor L (2015) From guide to target: molecular insights into eukaryotic RNA-interference machinery. Nat Struct Mol Biol 22:20-28

16. Denzler R, McGeary SE, Title AC, Agarwal V, Bartel DP, Stoffel M (2016) Impact of microRNA levels, target-site complementarity, and cooperativity on competing endogenous RNA-regulated gene expression. Mol Cell 64: 565-579

17. Kartha RV, Subramanian S (2014) Competing endogenous RNAs (ceRNAs): new entrants to the intricacies of gene regulation. Front Genet 5:8

18. Braun JE, Truffault V, Boland A, Huntzinger E, Chang CT, Haas G et al (2012) A direct interaction between DCP1 and XRN1 couples mRNA decapping to 5' exonucleolytic degradation. Nat Struct Mol Biol 19:1324-1331

19. Truesdell SS, Mortensen RD, Seo M, Schroeder JC, Lee JH, LeTonqueze O et al (2012) MicroRNA-mediated mRNA translation activation in quiescent cells and oocytes involves recruitment of a nuclear microRNP. Sci Rep 2:842

20. Brien JO, Hayder H, Zayed Y, Peng C (2018) Overview of microRNA biogenesis, mechanisms of actions, and circulation. Front Endocrinol 9:402

21. Croce CM (2009) Causes and consequences of microRNA dysregulation in cancer. Nat Rev Genet 10:704-714

22. Munker R, Calin GA (2011) MicroRNA profiling in cancer. Clin Sci (Lond) 121: $141-158$

23. Krek A, Grun D, Poy MN, Wolf R, Rosenberg L, Epstein EJ et al (2005) Combinatorial microRNA target predictions. Nat Genet 37:495-500

24. Hatley ME, Patrick DM, Garcia MR, Richardson JA, Bassel-Duby R, Van Rooij E et al (2010) Modulation of K-Ras-dependent lung tumorigenesis by MicroRNA-21. Cancer Cell 18:282-293

25. Meng F, Henson R, Wehbe-Janek H, Ghoshal K, Jacob ST, Patel T (2007) MicroRNA-21 regulates expression of the PTEN tumor suppressor gene in human hepatocellular cancer. Gastroenterology 133:647-658
26. Asangani IA, Rasheed SA, Nikolova DA, Leupold JH, Colburn NH, Post S, Allgayer H (2008) MicroRNA-21 (miR-21) post-transcriptionally downregulates tumor suppressor Pdcd4 and stimulates invasion, intravasation and metastasis in colorectal cancer. Oncogene 27:2128-2136

27. Zhu S, Wu H, Wu F, Nie D, Sheng S, Mo Y (2008) MicroRNA-21 targets tumor suppressor genes in invasion and metastasis. Cell Res 18:350-359

28. Calin GA, Liu CG, Sevignani C, Ferracin M, Felli N, Dumitru CD et al (2004) MicroRNA profiling reveals distinct signatures in B cell chronic lymphocytic leukemias. Proc Natl Acad Sci U S A 101:11755-11760

29. Eis PS, Tam W, Sun L, Chadburn A, Li Z, Gomez MF et al (2005) Accumulation of miR-155 and BIC RNA in human B cell lymphomas. Proc Natl Acad Sci U S A 102:3627-3632

30. Chen L, Cui B, Zhang S, Chen G, Croce CM, Kipps TJ (2008) Association between the proficiency of $\mathrm{B}$-cell receptor signaling and the relative expression levels of ZAP-70, SHIP-1, and Mir-155 in chronic lymphocytic leukemia. Blood 112:3155

31. Babar IA, Cheng CJ, Booth CJ, Liang X, Weidhaas JB, Saltzman WM, Slack FJ (2012) Nanoparticle-based therapy in an in vivo microRNA-155 (miR-155)dependent mouse model of lymphoma. Proc Natl Acad Sci U S A 109: e1695-e1704

32. Garzon R, Calin GA, Croce CM (2009) MicroRNAs in cancer. Annu Rev Med 60:167-179

33. Bader AG, Brown D, Winkler M (2010) The promise of microRNA replacement therapy. Cancer Res 70:7027-7030

34. Bui TV, Mendell JT (2010) Myc: maestro of microRNAs. Genes Cancer 1:568-575

35. Chang TC, Yu D, Lee YS, Wentzel EA, Arking DE, West KM, Dang CV, Thomas-Tikhonenko A, Mendell JT (2008) Widespread microRNA repression by myc contributes to tumorigenesis. Nat Genet 40:43-50

36. Chang CJ, Chao CH, Xia W, Yang JY, Xiong Y, Li CW, Yu WH, Rehman SK, Hsu JL, Lee HH, Liu M, Chen CT, Yu D, Hung MC (2011) p53 regulates epithelial-mesenchymal transition and stem cell properties through modulating miRNAs. Nat Cell Biol 13:317-323

37. Yamakuchi M, Lotterman CD, Bao C, Hruban RH, Karim B, Mendell JT, Huso D (2010) Lowenstein CJ P53-induced microRNA-107 inhibits HIF-1 and tumor angiogenesis. Proc Natl Acad Sci U S A 107:6334-6339

38. Bushati N, Cohen SM (2008) MicroRNAs in neurodegeneration. Curr Opin Neurobiol 18:292-296

39. Nelson PT, Wang WX, Rajeev BW (2008) MicroRNAs (miRNAs) in neurodegenerative diseases. Brain Pathol 18:130-138

40. Karkhane M, Lashgarian HE, Hormozi M, Fallahi S, Cheraghipour K, Marzban A (2020) Oncogenesis and tumor inhibition by microRNAs and its potential therapeutic applications: a systematic review. MicroRNA 9:198-215

41. Lu J, Getz G, Miska EA, Alvarez-Saavedra E, Lamb J, Peck D, Sweet-Cordero A, Ebert BL et al (2005) MicroRNA expression profiles classify human cancers. Nature 435:834-838

42. Olson P, Lu J, Zhang H, Shai A, Chun MG, Wang Y, Libutti SK, Nakakura EK, Golub $T R$, Hanahan D (2009) MicroRNA dynamics in the stages of tumorigenesis correlate with hallmark capabilities of cancer. Genes Dev 23:e2152-e2165

43. Ferracin $M$, Pedriali $M$, Veronese A, Zagatti B, Gafa R, Magri E, Lunardi M, Munerato $G$ et al (2011) MicroRNA profiling for the identification of cancers with unknown primary tissue-of-origin. J Pathol 225:43-53

44. Rosenfeld N, Aharonov R, Meiri E, Rosenwald S, Spector Y, Zepeniuk M, Benjamin $\mathrm{H}$ et al (2008) MicroRNAs accurately identify cancer tissue origin Nat Biotech 26:462-469

45. Schwarbzbach AE, Adai AT, Lee LS, Conwell DL, Andruss BF (2011) Development of a miRNA-based diagnostic assay for pancreatic ductal adenocarcinoma. Expert Rev Mol Diagn 11(3):249-257

46. O'Neill $\sqcup J$ (2008) A renaissance of interest innate immunity: will new treatments for rheumatoid arthritis emerge? Future Rheumatol 3:203-205

47. Eyileten C, Wicik Z, Rosa SD, Mirowska-Guzel D, Soplinska A, Indolfi C et al (2018) MicroRNAs as diagnostic and prognostic biomarkers in ischemic stroke-a comprehensive review and bioinformatic analysis. Cells 7:249

48. Li Y, Maegdefessel L (2016) My heart will go on-beneficial effects of antiMiR-30 after myocardial infarction. Ann Transl Med 4:144

49. Gacon J, Kablak-Ziembicka A, Stepien E, Enguita FJ, Karch I, Derlaga B et al (2016) Decision-making microRNAs (miR-124, -133a/b, -34a and -134) in patients with occluded target vessel in acute coronary syndrome. Kardiol Pol 74:280-288

50. Zeller T, Keller T, Ojeda F, Reichlin T, Twerenbold R, Tzikas S et al (2014) Assessment of microRNAs in patients with unstable angina pectoris. Eur Heart J 35:2106-2114 
51. Goren Y, Meiri E, Hogan C, Mitchell H, Lebanony D, Salman N et al (2014) Relation of reduced expression of MiR-150 in platelets to atrial fibrillation in patients with chronic systolic heart failure. Am J Cardiol 113:976-981

52. Schetter AJ, Leung SY, Sohn JJ, Zanetti KA, Bowman ED, Yanaihara N et al (2008) MicroRNA expression profiles associated with prognosis and therapeutic outcome in colon adenocarcinoma. JAMA 299:425-436

53. Egyed B, Kutszegi N, Sagi JC, Gezsi A, Rzepiel A, Visnovitz T et al (2020) MicroRNA-181a as novel liquid biopsy marker of central nervous system involvement in pediatric acute lymphoblastic leukemia. J Transl Med 18:250

54. Zonneveld AJ, Au YW, Stam W, Gelderen SV, Rotmans Jl, Peter MT, Deen et al (2020) MicroRNA-132 regulates salt-dependent steady-state renin levels in mice. Commun Biol 3:238

55. Liu Z, Zhang XH, Callejas-Diaz B, Mullol J (2016) MicroRNA in united airway diseases. Int J Mol Sci 17(5):716

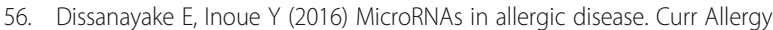
Asthma Rep 16:67

57. Mehta MD, Liu PT (2014) MicroRNAs in mycobacterial disease: friend or foe? Front Genet 5:231

58. Anglicheau D, Sharma VK, Ding R, Hummel A, Snopkowski C, Dadhania D et al (2009) MicroRNA expression profiles predictive of human renal allograft status. Proc Natl Acad Sci U S A 106:5330-5335

59. Xiao B, Wang Y, Li W, Baker M, Guo J, Corbet K et al (2013) Plasma microRNA signature as a non-invasive biomarker for acute graft-versus-host disease. Blood 122(19):3365-3375

60. Bohm-Hofstatter $H$, Tschernutter M, Kunert R (2010) Comparison of hybridization methods and real-time PCR: their value in animal cell line characterization. Appl Microbiol Biotechnol 87:419-425

61. Reue K (1998) mRNA quantitation techniques: considerations for experimental design and application. J Nutr 128:2038-2044

62. Chen C, Ridzon DA, Broomer AJ, Zhou Z, Lee DH, Nguyen JT et al (2005) Real-time quantification of microRNAs by stem-loop RT-PCR. Nucleic Acids Res 33:e179

63. Kang K, Peng X, Luo J, Gou D (2012) Identification of circulating miRNA biomarkers based on global quantitative real-time PCR profiling. J Anim Sci Biotechnol 3:4

64. Pritchard CC, Cheng HH, Tewari M (2012) MicroRNA profiling: approaches and considerations. Nat Rev Genet 13:358-369

65. Jiang $L$, Duan D, Shen $Y$ et al (2012) Direct microRNA detection with universal tagged probe and time-resolved fluorescence technology. Biosens Bioelectron 34:291-295

66. Duan D, Zheng KX, Chen Y et al (2011) Label-free high-throughput microRNA expression profiling from total RNA. Nucleic Acids Res 39:e154

67. Vedarethinam I, Shah P, Dimaki M et al (2010) Metaphase FISH on a chip: miniaturized microfluidic device for fluorescence in situ hybridization. Sensors 10:9831-9846

68. Kwasny D, Vedarethinam I, Shah P et al (2012) Advanced microtechnologies for detection of chromosome abnormalities by fluorescent in situ hybridization. Biomed Microdevices 14:453-460

69. Kao KJ, Tai CH, Chang WH et al (2015) A fluorescence in situ hybridization (FISH) microfluidic platform for detection of HER2 amplification in cancer cells. Biosens Bioelectron 69:272-279

70. Moldovan L, Batte KE, Trgovcich J, Wisler J, Marsh CB, Piper M (2014) Methodological challenges in utilizing miRNAs as circulating biomarkers. J Cell Mol Med 18:371-390

71. Yang H, Hui A, Pampalakis G, Soleymani L, Liu FF, Sargent EH, Kelley SO (2009) Direct, electronic microRNA detection for the rapid determination of differential expression profiles. Angew Chem Int Ed Engl 48:8461-8464

72. Roy S, Soh JH, Gao ZA (2011) Microfluidic-assisted microarray for ultrasensitive detection of miRNA under an optical microscope. Lab Chip 11:1886-1894

73. Dong H, Jin S, Ju H, Hao K, Xu LP, Lu H, Zhang X (2012) Trace and label-free microRNA detection using oligonucleotide encapsulated silver nanoclusters as probes. Anal Chem 84:8670-8674

74. Tran HV, Piro B, Reisberg S, Tran LD, Duc HT, Pham MC (2013) Label-free and reagentless electrochemical detection of microRNAs using a conducting polymer nanostructured by carbon nanotubes: application to prostate cancer biomarker miR-141. Biosens Bioelectron 49:164-169

75. Peterson SM, Thompson JA, Ufkin ML, Sathyanarayana P, Liaw L, Congdon CB (2014) Common features of microRNA target prediction tools. Front Genet 1:1-10

76. Karreth FA, Pandolfi PP (2013) CeRNA cross-talk in cancer: when ce-bling rivalries go awry. Cancer Discov 3:1113-1121
77. Dave VP, Ngo TA, Pernestig A, Tilevik D, Kant K, Nguyen T et al (2019) MicroRNA amplification and detection technologies: opportunities and challenges for point of care diagnostics. Lab Invest 99:452-469

78. Sajid M, Kawde AN, Daud M (2015) Designs, formats and applications of lateral flow assay: a literature review. J Saudi Chem Soc 19:689-705

79. Tripathi P, Upadhyay N, Nara S (2018) Recent advancements in lateral flow immunoassays: a journey for toxin detection in food. Crit Rev Food Sci Nutr 58:1715-1734

80. Hou SY, Hsiao YL, Lin MS et al (2012) MicroRNA detection using lateral flow nucleic acid strips with gold nanoparticles. Talanta 99:375-379

81. Gao X, Xu LP, Wu T et al (2016) An enzyme-amplified lateral flow strip biosensor for visual detection of microRNA-224. Talanta 146:648-654

82. Feng C, Mao X, Shi H et al (2017) Detection of microRNA: a point-of-care testing method based on a pH-responsive and highly efficient isothermal amplification. Anal Chem 89:6631-6636

83. Choi Y, Metcalf G, Sleiman MH et al (2014) Oligonucleotide-templated reactions based on peptide nucleic acid (PNA) probes: concept and biomedical applications. Bioorg Med Chem 22:4395-4398

84. Metcalf GAD, Shibakawa A, Pate $\mathrm{H}$ et al (2016) Amplification-free detection of circulating microRNA biomarkers from body fluids based on fluorogenic oligonucleotide-templated reaction between engineered peptide nucleic acid probes: application to prostate cancer diagnosis. Anal Chem 88:8091-8098

85. Degliangeli F, Kshirsagar P, Brunetti $V$ et al (2014) Absolute and direct microRNA quantification using DNA-gold nanoparticle probes. J Am Chem Soc 136:2264-2267

86. Hamidi-asl E, Palchetti I, Hasheminejad E et al (2013) A review on the electrochemical biosensors for determination of microRNAs. Talanta 115:74-83

87. Mollaei H, Safaralizadeh R, Rostami Z (2019) MicroRNA replacement therapy in cancer. J Cell Physiol 234(8):12369-12384

88. Kobayashi M, Sawada K, Kimura T (2018) Is microRNA replacement therapy promising treatment for cancer? Non-coding RNA Investig 2:56

89. Iorio M, Casalini P, Piovan C, Braccioli L, Tagliabue E (2012) Current and future developments in cancer therapy research: miRNAs as new promising targets or tools. In: Bologna M (ed) Biotargets of cancer in current clinical practice. Humana Press, Milan, pp 517-546

90. Haussecker D, Kay MA (2010) miR-122 continues to blaze the trail for microRNA therapeutics. Mol Ther 18:240-242

91. Lanford RE, Hildebrandt-Eriksen ES, Petri A, Persson R, Lindow M, Munk ME et al (2010) Therapeutic silencing of microRNA-122 in primates with chronic hepatitis C virus infection. Science 327:198-201

92. Janssen HL, Reesink HW, Lawitz EJ, Zeuzem S, Rodriguez-Torres M, Patel K et al (2013) Treatment of HCV infection by targeting microRNA. N Engl J Med 368:1685-1694

93. Pagotto S, Veronese A, Soranno A et al (2018) Hsa-miR-155-5p drives aneuploidy at early stages of cellular transformation. Oncotarget 9(16):13036-13047

94. Alivernini S, Gremese E, McSharry C et al (2018) MicroRNA-155—at the critical interface of innate and adaptive immunity in arthritis. Front Immunol 8:1932

95. Wiggins JF, Ruffino L, Kelnar K, Omotola M, Patrawala L, Brown D et al (2010) Development of a lung cancer therapeutic based on the tumor suppressor microRNA-34. Cancer Res 70:5923-5930

96. Trang P, Medina PP, Wiggins JF, Ruffino L, Kelnar K, Omotola M et al (2010) Regression of murine lung tumors by the let-7 microRNA. Oncogene 29:1580-1587

97. Kitade Y, Akao Y (2010) MicroRNAs and their therapeutic potential for human diseases: microRNAs, miR-143 and -145, function as anti-oncomirs and the application of chemically modified miR-143 as an anti-cancer drug. J Pharmacol Sci 114:276-280

98. Pramanik D, Campbell NR, Karikari C, Chivukula R, Kent OA, Mendell JT, Maitra A (2011) Restitution of tumor suppressor microRNAs using a systemic nanovector inhibits pancreatic cancer growth in mice. Mol Cancer Ther 10:1470-1480

99. Wang $H$, Jiang $Y$, Peng $H$, Chen $Y$, Zhu P, Huang $Y$ (2015) Recent progress in microRNA delivery for cancer therapy by non-viral synthetic vectors. Adv Drug Deliv Rev 81:142-160

100. Wu Y, Crawford M, Yu B, Mao Y, Nana-Sinkam SP, Lee $\sqcup$ (2011) MicroRNA delivery by cationic lipoplexes for lung cancer therapy. Mol Pharm 8(4):1381-1389

101. Takyar S, Vasavada H, Zhang JG, Ahangari F, Niu N, Liu Q et al (2013) VEGF controls lung Th2 inflammation via the miR-1-Mpl (myeloproliferative leukemia virus oncogene)-P-selectin axis. J Exp Med 210:1993-2010

\section{Publisher's Note}

Springer Nature remains neutral with regard to jurisdictional claims in published maps and institutional affiliations. 